\title{
Remarks to the Reliability Assessment and to Human Actions - Especially Car Driver
}

\author{
Zbigniew Matuszak ${ }^{1,{ }^{*}, \text { Marek Jaśkiewicz }}{ }^{2}$, Dariusz Więckowski ${ }^{3}$, and Józef Stokłosa ${ }^{4}$ \\ ${ }^{1}$ Maritime University of Szczecin, Faculty of Marine Engineering, ul. Wały Chrobrego 1-2, 70-500 \\ Szczecin, Poland \\ ${ }^{2}$ Kielce University of Technology, Faculty of Mechatronics and Mechanical Engineering, al. \\ Tysiąclecia Państwa Polskiego 7, 25-314 Kielce, Poland \\ ${ }^{3}$ Automotive Industry Institute, ul. Jagiellońska 55, 03-301 Warszawa, Poland \\ ${ }^{4}$ University of Economics and Innovation in Lublin, ul. Projektowa 4, 20-209 Lublin, Poland
}

\begin{abstract}
The description attempt of the system person-vehicleenvironment as an element of the system person-technical objectenvironment has been made. In the system analysis the reliability of the machine exploiter - a car driver has been taken into account. It has been pointed out that technical system operators (in this case - the drivers) have to be considered important in the structure of reliability of these systems. The operational and biological reliability characteristic of a human being technical system operator has been carried out. The necessity for conducting different psychological tests for assessment of the quality of the human being - operator of each technical system - has been indicated.
\end{abstract}

\section{Introduction}

It is a human being who has the main impact on causing road accidents. When looking at the impact of the human factor exclusively on causing road accidents it equals $63 \%$, and counting it together with the impact of the environment (road) and the vehicle the value may reach $90 \div 95 \%$. The possibility that the vehicle was the mere cause of the accident is relatively small as it equals only few percent [1]. There has been a study showing the impact of the drivers on the road accidents reaching $36 \div 41 \%$ in a non-built-up area, $39 \div 53 \%$ in a built-up area, with the impact of the vehicle reaching $15 \div 25 \%$, and the impact of the environment being at the level of $38 \div 45 \%$ in a non-built-up area and $31 \div 34 \%$ in the city [2].

The majority of the statistical data shows a minor impact of both the vehicle and the environment on the road accident [3].

In many statistics, the impact of the environment can be omitted since a wet surface or a road covered with snow does not pose a direct threat these days. So the impact of the factors like bad surface condition or snow on the road on the accidents occurrence is quite low. Under normal road conditions an accident happens usually as a consequence of few

*Corresponding author: z.matuszak@am.szczecin.pl 
causes happening at the same time and which influence its beginning and further course of action. But definitely the driver can contribute to the accident to a greater extent [4].

All these factors play together so the straight-forward determination of the accident causes is not always possible. Complicated relationships between these factors, features to a particular accident and individual features of the driver contribute to the fact that speaking in general about particular causes is still difficult [4]. In order to present the figure of the driver different personal features, like for instance: concentration skills, intellectual abilities, resistance to stress, or reaction time are taken into consideration. They are often measured by means of special tests.

The reaction of a driver on the road situations can be different depending on the circumstances: it can be logical, illogical or irrational [1, 5-8]. During the logical behaviour his reactions can be overseen. But in other cases the driver can make turns not adjusting them to a given situation. Starting such turns or responding in a wrong way can escalate the danger [4]. Such spontaneous behaviour of the driver is often ascribed to less experienced drivers.

Such states of mind as vagueness, absence of mind, tiredness may provoke actions inconsistent with rational and logical thinking of the drivers. These, in turn, may spark the events directly leading to an accident. The risk of the danger caused by the driver occurring on the road is determined with many factors including his psychological and physiological features. These features can differ dynamically during the drive [4].

Psychological features may heighten or lower the level of risk that the accident will happen. They include, above all, ability to oversee things, ability to drive in a hazardous manner (for instance fast), maintaining common sense, kindness, hostility, neurotisation. Under physiological features we distinguish: condition of eyesight and hearing, level of tiredness, manual skills.

The features mentioned above are not ascribed to a particular driver for good. They may change dynamically depending on the conditions, for instance, time of the day, season, traffic conditions, etc. In the theory of human's reliability there are quantitative and qualitative definitions. The operator's reliability (in this case reliability of a driver) in the quantitative sense means the ability described by the probability to perform given tasks. In the qualitative sense though, according, it is the ability to perform tasks with the minimal risk of making a mistake and in a given time. Reliability may be understood as a function of adequacy between internal factors of the operator (temperamental features, personality, motivation, qualifications), and external factors (tasks, technical quality and machine exploitation, methods of work, physical environmental conditions, social climate, work atmosphere).

A person who is an element of the system person-machine-surrounding may be in general considered, among others, as [9]: machine operator in the utilising processes (pilot, driver, etc.); one operating the machine in the operating process (condition control, current and proactive repairs); element of the system realizing certain functions (explorer, observer); person using the machine functions (e.g. passenger of a particular means of transport). Seeing a person as an exploiter of a machine - technical device - it is of utmost importance to perform the operating actions both on time and without any faults. This affects the efficiency of the system and, in many cases, safety of the operator and other people as well as technical elements of the system or of the natural environment. Safety should characterize the whole system: a person affects system safety as much as deadline unfaithfulness, lack of precision, and failure of his actions generate emergency situations [10].

Fallibility of a person (people) during work in the marine environment is one of the main reasons of accidents and breakdowns. This fallibility usually stems from bad adaptation of objects themselves and their equipment to the needs and abilities of a human being. 
In assessment of the operator's work it is the result of his work and the way it has been achieved that count most, if it is significant from the perspective of processes taking place in the operating objects as well as the economy of their exploitation process. Sometimes also the time of realizing operating action is important, for example in the situations when the object condition changes quickly, like during turning of the operating installation and in emergency situations, in which the time of reaction to the external or internal events is crucial. It leads to the dichotomy of the reliability models of human beings: reliability which does not depend on time, and depends on time.

The model of reliability which does not depend on time looks as follows:

where:

$$
R=P(Z=1, W=1)
$$

$Z$ - discrete random variable so that:

$Z=1$ when the operator's task has been realized, and 0 when it has not;

$W$ - discrete random variable so that:

$W=1$ when the task was performer properly, and 0 - when improperly.

So the time-dependent reliability looks as follows:

where:

$$
R(t)=P(Z=1, T<t)
$$

$T$ - continuous random variable presenting the time of task realization by the operator;

$t$-positive real number so that $t \in R^{+}$.

Operator's reliability can be determined for the specific tasks. We state that a task consists of minimal collection of actions corresponding to exercises completion of which realizes a particular goal. Some actions must be preceded with other to be realized. It is also possible to have selective actions which are implemented to the task realization procedure only when it is necessary for realizing a task.

Model of reliability which does not depend on time corresponds to the routine actions performed in the process of ship installations, such as starting-up of some devices, setting them aside, switching devices and installations, changing of work parameters and settings of automation systems. Time-dependent reliability model is used for assessment of work of a ship mechanic (operator) in emergency situations or situations in which not completing a task within a given time results in posing a danger for installations and objects being around. One can distinguish cases in which mechanic's reaction to any interruptions or breakdowns includes only routine actions and cases in which he can rely only on his own knowledge. In most cases the time for task realization underlies log-normal distribution [11]. Operator's reliability according to [11] may be determined on the basis of the studies realized on simulators, since in natural conditions one is not able to achieve necessary data to estimate operator's reliability characteristics. It is so due to the fact that the tasks he performs in difficult situations may cause waste.

\section{The attempt of determining human reliability}

A human being is a system of high level of complexity with excess reliability structure [9]. From the cybernetic point of view this system can be seen as autonomous as it is able to perform self-control and to counteract against losing the ability to control. Besides this, it is capable to keep functional balance regardless of the changes in the surrounding and it aims at maintaining its existence as well as acts on behalf of its own interests.

In the human organism all the functions of autonomous system are performed. These are [9]: affecting the surrounding (effectors), receiving information from the outside (receptors), consumption of energy from the outside (alimentator), storing and processing 
information (correlator), processing and storing energy (accumulator), maintaining functional balance (homeostat).

A person, from the reliability point of view can be characterized with: the mistakes of receiving information from the outside (it can result from imperfection of receptors and interruptions of the information taken from the outside); mistakes of processing information what can result from the excessive amount of information which exceeds the capabilities of correlator or not preparing the correlator to process certain information; mistakes or insufficient interfering with the surrounding what may stem from the deterioration of the functional balance or exceeding the abilities of the effectors; losing or limiting the ability to act, as a result of damage of the organs or losing or limiting the ability to adapt to the changes going on in the surrounding.

From the point of view of the mentioned features one may assess such human reliability traits like faultlessness and effectiveness. Both of them determine human operational reliability and faultlessness determines biological reliability.

Human biological reliability is the ability to act in a given period of time and in given conditions of influence of the surrounding. It is measured by the probability of maintaining the ability to act in a given period of time and in given conditions. When we use the technical term "damage" to describe a human being, we may use the notion of reversible damage (for instance, a temporary loss of the ability to act due to stressful situations or an illness) or non-reversible damage (for example, improper functioning of some of the internal organs of a human body).

Reliability of human work can be measured with the probability of success in the work or task realization on a given level of system functioning, in a given time period, described with the requirement about the duration of work.

A proper functioning means to fulfil the task in a given time. Improper functioning, on the other hand, may be the reason for the machine breakdown or may change the course of fulfilling the task. A person is characterized with a certain time of receiving information $T_{1}$ (which depends on the abilities of receptors), time for information analysis $T_{2}$ (which depends on the abilities of correlator), decision making time $T_{3}$ (which depends on the cooperation between correlator and effector), decision performing time $T_{4}$ (which depends on the abilities of the effector). A task will be performed on time if a predefined time dedicated to perform the task will meet the inequality

$$
T_{1}+T_{2}+T_{3}+T_{4} \leq T_{0}
$$

where:

$T_{0}$ - predefined time dedicated to perform the task.

During realization of the following basic tasks (information receiving, information processing, decision making, decision performing) a person (exploiter, operator, ...) may make mistakes. The mistakes an exploiter of a technical system may encounter include: design mistakes depending on too low design quality; mistakes made by the crew not performing the expected tasks properly or performing unexpected procedures; executive mistakes appearing on the stage of manufacturing, resulting from bad quality of work, using incorrect material, producing the good without complying with the requirements; mistakes of technical operation in the exploitation process due to bad quality of repair or assembly; control mistakes, for instance, treating faulty product as a good one; storing mistakes relating to wrong stock keeping or transport.

Some reasons of incorrect acting of human being (exploiter) include: improper qualifications of a crew; performing wrong operating tasks; improper working conditions; insufficient or improper working tools; improper stimulation of a faultless work.

During the work of exploiter the probability of his faultless work is shown by the relation 


$$
R_{0}(t)=\exp \left[-\int_{0}^{t} \lambda_{0}(\tau) d \tau\right]
$$

where:

$\lambda_{0}(t)$ - intensity of making mistakes by a person in time $t$.

The ability of a person to correct their mistakes is the probability that a mistake acceptable at performing a task will be corrected after time $t$ at certain load and surrounding conditions corresponding to the realized task. The probability of correcting a mistake is presented by the relation

$$
R_{k b}(t)=\exp \left[-\int_{0}^{t} \mu(\tau) d \tau\right]
$$

where:

$\mu(t)$ - frequency of correcting a mistake.

Operating reliability of an operator-exploiter can be defined as a probability of performing a task comprising $\mathrm{N}$ actions on time and faultlessly and this might be described by the relation

$$
R_{0}=\left(\prod_{i=1}^{N} P_{i}\right) P\left(\sum_{i=1}^{N} T_{i} \leq T_{0}\right)
$$

where:

$P_{i}-$ probability of performing $i$-action properly,

$T_{i}$ - realization time of $i$-action,

$T_{0}$ - time for performing a task.

In case a crew acts under stress, the variables $T_{i}(i=1,2 \ldots ., N)$ are stochastically dependent, so the probabilities $P_{i}$ are functions of stress, so the practical application of the relation (6) becomes very difficult. For determining operational reliability the methods of computer simulation are used.

\section{Assessment of human activities}

In human activities modelling for the needs of integrated risk assessment of the system it is necessary to take these factors into account which affect human behaviour the most. They are called Performance Shaping Factors - PSF [12] and they can be divided into external and internal. External ones include whole working environment, especially construction of devices and machines, written and oral instructions. Internal PSF are connected to the individual features of people, their skills, motivation and expectations. Psychological and physiological stresses are the factor of working environment, where the requirements imposed on the person by the system are not compatible with his skills and limitations.

On the other hand, in human behaviour modelling four levels of stress factors can be distinguished [12] very low (insufficient to maintain a proper level of vigilance during performing the tasks); optimal (which makes performing the task easier); moderately high (hinders, but in a moderate way, to perform the tasks optimally); very high.

First three levels relate to the task stress connected to low, optimal, or high workload. The highest level is represented by the stress resulting from hazards, it is caused by the emotional reactions to the situation in which a task is being performed.

Being aware of the consequences of a mistake may decrease or increase the probability of making one. Often, the consequences of human mistakes may be compensated by other elements of the system or other human activities. It is a recovery factor - RF that controls it in the system. A human reservation is a typical example of this factor.

The specificity of driver's work requires to spend some time on the chosen functions and human organism functioning. 
A human organism realizes some activities, like for example ones connected to the brain activity by secretion of the glands, functions of the skeleton and muscle movements. As a result of a decision made by the nervous system the effect of movement may occur. Planning of a movement is a complex issue which includes: choosing a right muscle or their group and adjusting it or them to perform a certain movement or to ensure a proper position (tension); choosing the level of force; informing about the relation between the position of muscles and initial conditions of the movement; being precise in achieving a right track of movement; achieving a right speed of movement.

It is up to nerve centre, so the collection of neurons, whether the movement will occur, what the attention period (latent stimulation) for the movement there is and what force the effector will be stimulated with. During movement higher brain functions are realized: learning of movements, thinking which has a goal of movement as its criterion, movement memory whose criterion is based on the optimization of the movement; information circulation; comparison mechanism and its feedback; reactions tracking. During every work one can divide actions into movements: position movements, which include moving body parts from one position to another; repetitive - repeating of the same activity all of the time; continuous - taking place constantly in a given time; serial - many different, singular, quite independent movement units performed in certain order; static - performed by some, fixed muscle groups which do not contain movement elements (keeping them in a right position).

Reaction time is dependent, among others, on different factors: movement characteristics, signal characteristics (space and time features); type of a functioning factor and type of a sense used; relative intensity of the trigger evoking reaction both at the source of emission and on the side of a receiver (differentiating of a trigger with respect to the background); disturbance in the transfer channel; resistance power of an operated device; duration time of the trigger, meaning the way it accumulates and disappears; pause time in between the following signals; explicitness and amount of information carried by the signal; state of readiness of a person reacting; psychical and manual predisposition of the receiver; climate conditions; individual features of a receiver (his health state; eating habits, etc.).

\section{Conclusion}

In the reliability analysis of a human factor - the name which refers to the person in a technical system - three types of dominance behaviour can be distinguished:

- Proficiency in performing more or less aware or reflexive activities based on the remembered models of behaviour;

- Rules resulting from remembered or written principles compiled in case of occurring forecasted symptoms and exploitative situations;

- Knowledge including identification of the situations and states of the device on the basis of the received and processed information about the work parameters of devices and systems.

Estimating the reliability of a person as an element of the technical system one has to take a wide scope of factors into account:

- Probability of mistake which can occur at performing every operation included in the activity process;

- Possibility to forecast the most significant mistakes that can be made in the process of utilizing and operating of the devices;

- Frequency of breakdowns of devices and technical systems due to a human factor;

- Taking into consideration human mistakes which are reversible;

- Probability of the correct functioning of a device (system) in case of making a mistake. 
In the analysis of technical system reliability the damages caused by the operator are usually neglected if they do not involve high costs.

The circadian rhythm is the most important in adaptation of the living organisms to the conditions of the external world. Social factor for people and alteration of lightening for animals are its basic synchronizers. Deil rhythm of body temperature [2] was described as a first biological rhythm. It has a sinusoidal character. It shows maximum values in the afternoon hours and minimum values during the night with relatively high individual deviations.

Adaptation of living organisms to the environment takes place with the participation of biophysical factors of cyclical character. These factors are called synchronizers or time determinants, since they have major influence of the course of biorhythms. Diel rhythm is synchronized not only with light but also with other environmental influences. Thanks to the latter property and function the synchronizers are time donors, and their role is not equal. Chronobiologists rejected the idea of an external character of a diel rhythm. According to the studies by $[11,13]$ eliminating the alteration of phases: day (light) - night (darkness) does not result in the interruption of counting time by the human body, yet it interfered with it slightly. The length of day and night in such conditions differs by 1 hour from a 24-hour astronomical day and night. In this way a term circadian rhythms was coined. The majority of these rhythms is of endogenous character. It means they are not a passive reflection of the external world conditions but are deeply coded in the particular cells of the organism. These cells use their own biological clock which adjusts itself to the surrounding conditions. Different factors affect internal rhythm of physiological activities and they adjust the biological clock to the current surrounding conditions. For a human being it is not only photoecological factors or time of eating that play the role of synchronizers of biological rhythms. It is mainly social, civilization, and psychological factors called social synchronizers which are crucial here.

Among biological rhythms one may distinguish short, circadian weekly, monthly, seasonal and many-year rhythms.

According to [12] the methods of study of personality psychology may be divided into basic ones and auxiliary ones. Basic methods established and developed during the development of the psychology itself, and their methodological assumptions and technique were worked out by the psychologists.

Basic studying methods of personality psychology include, among others:

- Psychological observation allowing for the objective assessment of occurring certain activities and determining the course of these activities. The activities occurring spontaneously in the examined person are the subject of these observations;

- Psychological experiment allowing for evoking the activities examined, observing and measuring them;

- Analysis of the effects of the action which occurred during learning process. Such an analysis allows for collecting findings about the course of activity and personal features shown by the examined person;

- Psychological interview allowing for collecting information about the environment, life history, state of health, education and family situation. When the interview is properly directed one can see the reactions about the interests, emotions, attitudes and personal features;

- Introspection (self-observation) in which a person examined is asked questions about their mental experiences which is then a base for describing examined mental phenomena;

- Survey;

- Questionnaires and personal inventories, meaning improved and more comprehensive forms of surveys; 
- Tests allowing for measuring many different activities, mental functions and personal features; measuring the level of intelligence, skills, inclinations to mental disorders...

Putting all these studies together allows for the analysis of social contacts within a group and mechanisms underlying its functioning. Out of these three elements of the system person-vehicle-surrounding it is the vehicle which is the best known and best mathematically described. The influence of a road surrounding is described better and better. A clear disproportion is visible here. Yet, the activity of a diver-person is still not entirely analysed and much less modelled.

This paper is supported by the research project "From horse-drawn railway to intermodal transport" within Visegrad Fund.

\section{References}

1. J. Wicher, Bezpieczeństwo samochodów i ruchu drogowego (Warszawa: WKi屯, Poland, 2012)

2. A. Reński, Bezpieczeństwo czynne samochodu. Zawieszenia oraz układy hamulcowe $i$ kierownicze (Warszawa: Oficyna Wydawnicza Politechniki Warszawskiej. Poland, 2011)

3. L. Prochowski, et al., Podstawy rekonstrukcji wypadków drogowych (Warszawa: WKiÆ, Poland, 2014)

4. R.S. Jurecki, Badania i modelowanie reakcji kierowców w sytuacjach zagrożenia wypadkowego. Monografie Studia Rozprawy Nr M84 (Kielce: Wydawnictwo Politechniki Świętokrzyskiej, Poland, 2016)

5. T. Toledo, H.N. Koutsopoulos, M. Ben-Akiva, Transportation Research, Part C: Emerging Technologies 15, 2, 96-112 (2007)

6. G.N. Bifulco, L. Pariota, M. Brackstione, M. Mcdonald, Transportation Research, Part C: Emerging Technologies 36, 352-366 (2013)

7. R.G. Hoogendoorn, B. Arema, K.A. Brookhuis, Transportation Research, Part C: Emerging Technologies 36, 581-603

8. S.H. Hamdar, H.S. Mahmassani, M. Treiber, Transportation Research, Part B: Methodological, 78, 32-53 (2015)

9. L. Hempel, Człowiek i maszyna. Model techniczny współdziałania (Warszawa: WKiŁ, Poland, 1984)

10. J. Jaźwiński, J. Borgoń, Niezawodność eksploatacyjna i bezpieczeństwo lotów (Warszawa: WKiŁ, Poland, 1989)

11. E.M. Dougherty, J.R. Fragola, Human Reliability Analysis (New York: John Wiley \& Sons, USA, 1988)

12. P.H. Lindsay, D.A. Norman, Procesy przetwarzania informacji u czlowieka. Wprowadzenie do psychologii (Warszawa: PWN, Poland, 1984)

13. T. Dzierżykray-Rogalski, Rytmy $i$ antyrytmy biologiczne (Warszawa: Wiedza Powszechna, Poland, 1986) 